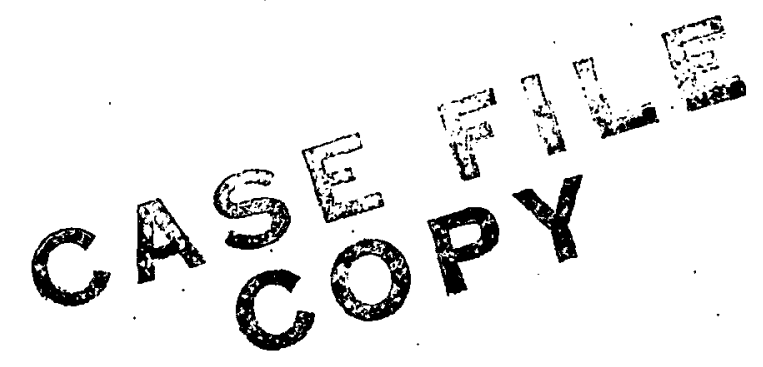

AIRBREATHING ENGINES FOR SPACE SHUTTLE

by Arthur J. Glassman, Warner L. Stewart, and Stanley M. Nosek Lewis Research Center Cleveland, Ohio

TECHNICAL PAPER proposed for presentation at National Aerospace Engineering and Manufacturing Meeting sponsored by the Society of Automotive Engineers San Diego, California, October 2-5, 19.72 and 1972 JANNAF Propulsion Meeting New Orleans, Louisianna, November 27-29, 1972 


\section{AIRBREATHING ENGINES FOR SPACE SHUTTLE}

by Arthur J。Glassman, Warner L。Stewart, and Stanley M. Nosek

National Aeronautics and Space Administration

Lewis Research Center

Cleveland, Ohio

ABSTRACT

The requirements imposed on the airbreathing engines by the shuttle mission and some results from engine design studies are discussed. In particular, some of the engine system weight study results are presented, potential problem areas and required engine modifications are identified, and testing requirements for a development and qualification program are discussed. The engines of interest for the shuttle are engines that are currently being developed for other applications. The potential problems, engine modifications, and testing requirements result primarily from the new environments associated with launch, space residence, and reentry.

\section{INTRODUCTION}

For the past several years, NASA has been engaged in definition and design studies, both inhouse and under contract, for a reusable space transportation system, known as the shuttle. Development of the shuttle was initiated this year. The shuttle system is intended to transport payloads into earth orbit and to return to earth at an overall cost greatly reduced from that of current systems. The shuttle vehicles must perform as launch vehicles, as spacecraft, and last, but not least, as aircraft.

To provide propulsion for the various aircraft functions, airbreathing gas turbine engines will be used. Thus, it was necessary to determine which airbreathing engines are most suitable for the shuttle, and to examine these engines with respect to the modifications and technology 
required to meet the shuttle mission environments. To do this, contracts were awarded to General Electric and Pratt \& Whitney to study the use of existing, developmental, and new engines.

In this paper, the requirements imposed on the airbreathing engines by the shuttle mission are reviewed. Then, various aspects of the engine design studies are discussed. Included in the discussion are resuits of the engine system parametric weight studies, possible problem areas and required engine modifications, and the nature of testing required for an engine development program.

\section{MISSION AND ENGINE REQUIREMENTS}

Since the beginning of the shuttle system studies, the study concepts and assumptions have undergone many changes. These changes have af fected the airbreathing engine requirements and, thus, the airbreathing engine studies were usually one step behind the vehicle studies. At the beginning and throughout most of the vehicle Phase B studies, the system was based on the use of a recoverable flyback booster and the mission flight profile was as shown in figure 1(a). After launch and staging, the first stage, or booster vehicle, reenters the atmosphere downrange and must cruise back to the launch site and make a horizontal landing. The second stage, or orbiter vehicle proceeds to orbit. Upon deorbiting, the orbiter reenters the atmosphere, descends directly back to the launch site, and makes a horizontal landing.

The engine requirements associated with this previous study mission are shown in Table $I$. They will be discussed here because they did serve as the basis for the airbreathing engine design studies. After spending a few minutes on the fringes of space and then reentering the atmosphere, 
the booster had to cruise 400 to 450 nautical miles (about 2 hours) back to the launch site. The orbiter, after spending 7 to 30 days in space, had no cruise requirement upon return. The booster cruise requirement made engine fuel consumption a very important consideration. As a result, NASA originally specified that hydrogen, because of its high energy content per unit mass and on-board availability, be given primary consideration as the airbreathing engine fuel . Fuel tradeoff studies $\left(\mathrm{H}_{2}\right.$ versus JP) made by the vehicle contractors showed that the use of $\mathrm{H}_{2}$ does result in a reduction in gross lift-off weight and vehicle dry weights; however, this is offset by the higher development cost, greater development risk, greater safety hazard, and more complex requirements for logistic support. On the basis of these factors as well as overall cost effectiveness, the air breathing engine fuel was changed to JP.

Both vehicles had to have self-ferry capability. Also, they had to be able to recover from an aborted landing attempt and circle the field to make another landing approach. Sufficient thrust had to be provided so that all parts of the missions (both orbital and ferry) could be flown with one engine out. The engines had to start reliably in-flight after, in the case of the orbiter, prolonged exposure to space. In order to meet the shuttle vehicle flight-test schedule, the first engines had to be available for delivery in 1975.

As a result of all the predevelopment studies and considerations, the system concept changed. The flyback booster was replaced by two strapon solid rocket motors, and an orbiter configuration having an expendable external $\mathrm{H}_{2}-\mathrm{O}_{2}$ tank was adopted. The currently-envisioned mission flight profile is as shown in figure $1(\mathrm{~b})$. The orbiter engines and the two 
strap-on solid-rocket motors are fired simultaneously。 After burnout, the solid booster motors separate and descend by parachute for recovery. The orbiter continues its ascent to orbit and, once there, jettisons the external $\mathrm{H}-\mathrm{O}$ tank. Upon deorbiting, the orbiter reenters the atmosphere, loiters a while to survey the landing situation, and then descends and makes a horizontal landing.

The engine requirements associated with the current mission are also presented in Table I along with those for the previous mission. With no flyback booster, there is no long cruise requirement, but only a 15 minute loiter at 10000 feet. The fuel is still JP as selected previously, and the residence time in orbit has not changed. Go-around and engineout requirements are no longer specified for the orbital mission flights, but only for the ferry flights where additional or different engines are allowed. The first engines for vehicle flight tests are still required in 1975 . Some of the current missions involve removal of the airbreathing engines from the orbiter in order to increase payload. For these particular missions, the orbiter must give up its loiter and glide-path control capabilities. In order to be able to fly some missions with engines on and some with engines off, and to be able to add engines for ferry, the orbiter must be built with provisions for relatively easy mounting and removal of air breathing engines.

In order to protect the engines from the space and reentry environments, it is desirable to stow the engines during the mission and then deploy them before use. This can be done in a number of different ways and with engines at different locations, as illustrated by figures 2 and 3. Figure 2 shows one of the designs proposed by McDonnell 
Douglas. The four nonaugmented engines are stowed upside down in the bottom of the payload bay and are deployed by swinging down and out. Figure 3 shows a design proposed by North American. The two augmented engines are stowed in the sides of the payload bay and swing up and out for deployment.

\section{ENGINE DESTGN STUDIES}

As part of the shuttle technology program being conducted by NASA, engine study contracts were awarded to General Electric and Pratt \& Whitney in June 1970. This was the time that the vehicle Phase B studies began, and the engine studies were based on the shuttle system concept being considered at that time. This included the flyback booster and the use of hydrogen as airbreathing engine fuel. As a result of the subsequent change to JP fuel in November 1970, these contracts were extended to also cover JP-fueled engines. The current shuttle concept, with solidrocket boosters and orbiter external $\mathrm{H}-\mathrm{O}$ tank as shown in figure $1(\mathrm{~b})$, was adopted too late to be considered in these airbreathing engine design studies.

The first objective of these studies was to identify candidate engines on the basis of performance potential。 Engine system weights were determined for existing engines, engines currently under development, advanced derivatives of developmental engines, and parametrically optimized new engines for both the booster and the orbiter. In order to identify required engine modifications and potential problem areas associated with the shuttle application, one engine of each contractor was then selected and subjected to a detailed design study. Finally, engine development and associated qualifi cation programs were identified in terms of both time and cost, and per formance specifications were determined for both the $\mathrm{H}_{2}$ and JP versions 
of the modified engines. Some of the results of these contract studies are reviewed herein.

\section{Engine System Weight Analysis}

Using vehicle design and mission profile information supplied by the vehicle contractors, the engine contractors determined engine, installation, fuel, and fuel tank weights for the selected study engines. Typical booster and orbiter missions used for the engine studies are presented in Table II. For the booster, the key part of the mission from the standpoint of fuel consumption is the cruise back to launch site. Cruise and abort are about equally critical from the standpoint of engine sizing or number. For the orbiter, the abort and go-around are the key parts of the mission.

The study engines were selected so as to cover a range of bypass ratios, and the effect of bypass ratio on engine system weight is shown in figure 4 for both the booster and the orbiter using JP fuel. The indicated weights are for 10 to 12 engines in the booster and 4 engines in the orbiter, and the results obtained by both contractors are included within the shaded areas shown. Slightly different weights and trends obtained by each contractor accounts for the spread and shape of the results. For the booster, engine system weight decreases with increasing bypass ratio over the range shown. This trend is caused by the cruise fuel consumption, which decreases with increasing bypass ratio, being a large part of the total weight. The use of a too-high bypass ratio, however, might not be tolerable from a standpoint of engine installation and deployment because of the increasing engine diameter with increasing bypass ratio. For the orbiter, a low to moderate bypass ratio appears desirable. This is due to engine weight rather than fuel weight being the major contributor to overall weight. 
For minimizing engine development and other costs and complexities, there was a strong desire to use a common engine for both vehicles. The results from figure 4 for both vehicles can be combined in terms of an equivalent payload penalty as

equivalent payload penalty $=\frac{\text { booster eng sys wt, }}{5}+$ orbiter eng sys wt。

This formula results from vehicle system studies that showed the booster weight to orbiter payload ratio to be about 5 . The effect of bypass ratio on equivalent payload penalty is shown in figure 5. For bypass ratios above 2, there appears to be little effect of bypass ratio on payload penalty. For bypass ratios below 2, there is a small increase in penalty with decreasing bypass ratio.

In general, the specific study results indicated that the engine system weight savings associated with the use of separate engines rather than a common engine do not justify the additional costs and complexities of using separate engines for the booster and orbiter vehicles. Further, the weight savings associated with optimized new engines as compared to engines currently under development do not appear sufficient to justify a new engine development.

Engine Modification and Development Requirements

In order to identify potential problem areas, required engine modifications, and a development and qualification program, one engine of each contractor was selected for detailed study. The engine selections were made on the basis of performance potential, cost, and projected availability. A nonaugmented version of the F401 engine, a low bypass ratio 
turbofan currently under development, was selected by NASA for the Pratt \& Whitney study. This engine is shown in figure 6. The after burner and variable nozzle have been removed and a fixed nozzle sketched in. The base F401 engine is scheduled for preliminary flight rating test (PFRT) at the end of December 1972 .

The selected Generai Electric engine was a nonaugmented version of the F101 engine, a moderate bypass ratio turbofan currently under development. A sketch of this engine, with the afterburner arid variable nozzle replaced by a fixed nozzle, is shown in figwre 7 . The base F101 engine is scheduled for PFRT in October 1973. Both the F401 and F101 engines are being developed for military applications.

The detailed studies of these engines identified potential problems and engine modifications resulting from the shuttle mission requirements. These potential problems and engine modifications are summarized in Table III and will be briefly reviewed here. Some of the major items are discussed in more detail in reference (1) ${ }^{*}$ 。

The vibration and $g$-loading during launch with the engines vertical could possibly cause brinelling and/or fretting in the bearings and damage to the shaft seals. The hard vacurum of space could result in oil and fuel vaporization, which could leave harmful deposits, outgassing of nonmetallics, which could degrade these materials, and cold welding of metal surfaces, such as in the bearings. The oil vaporization problem is considered to be quite real, and it is proposed to contain the oil in an isolated tank until the engines are started. The low

\footnotetext{
* Numbers in parentheses designate references at end of paper.
} 
temperature of space, if the engine temperature environment is not controlled, could result in the oil becoming very viscous or even freezing. It is proposed to heat the oil either by immersion heater or circulation. The inflight start requirement at altitudes of 20000 to 40000 feet raises concerns about combustor lightoff and engine acceleration by windmilling. A starter must be provided to assure acceleration to idle speed. The bearings will probably be dry during the first minute or so of engine start and damage could possibly occur.

The shuttle derivatives studied were unaugmented and had only subsonic flight requirements. Thus, the afterburner along with its associated fuel system and the variable exhaust nozzle can be removed from the engine, and a simple fixed nozzle can be used. The control system must be adjusted accordingly. The shorter operating life of the shuttle engine as compared to the base engine resulted in the specification of a higher maximum operating temperature for the shuttle version. Com bustor and turbine life and combustor temperature profile, therefore, become areas of concern.

Whether the potential problems are actually real problems will be determined by the engine development and qualification program. It is felt that a reasonable length of time for such a program from go-ahead to qualification is three years. The program, of course, can be accelerated, within limits, or stretched out with appropriate adjustments in required hardware and cost. This development and qualification program will consist of both component tests and engine tests. Since the base versions of both engines being considered are scheduled for PFRT within the next year and are then to proceed through testing toward 
military qualification, the qualification testing of the shuttle version of the engines need only be directed at those items specifically related to shuttle. The major types of component tests required are shown in Table IV. These tests would start shortly after program go-ahead. The modified control system must be calibrated and bench tested for all shuttle flight conditions, especially inflight start. This inflight start condition testing is particularly important if the fuel control will be dry during the orbital phase of the mission. The bearing rig test program would include repeated vibratory (launch simulation), dry acceleration (inflight start sim ulation), and lubricated endurance testing to evaluate bearing life for simulated space shuttle operation for the required number of missions. The most critical face-type seals would also undergo the vibratory and dry acceleration tests in a seal rig.

Model designs would be prepared for each candidate nozzle type and cold-flow wind tunnel models would be tested over the expected operating ranges of Mach number and pressure ratio. Hot flow models would undergo static rig testing. Mixers would also be evaluated. With regard to the combustor, the increase in exit temperature would require combustor testing to assure uniform exit temperature patterns and acceptable metal temperatures. Also, to achieve reliable inflight starts, performance testing would be done in the areas of lightoff and blowout boundaries at low inlet temperature and pressure conditions and with reduced mass flow rates.

Lubrication system tests would evaluate space storage and inflight start activation characteristics. The isolated oil tank along with the isolation valves and other parts of the system would be bench tested to 
evaluate vacuum sealing ability, system activation procedures, and required oil transfer time. Since the base engines were not designed with vacuum exposure as a requirement, some of the materials may require replacement. Certain platings are known to vaporize in vacuum and substitutes would have to be found. Other materials, such as plastics and seal and gasket materials, would be exposed to a simulated space vacuum and subjected to bench tests to determine weight loss, property changes, and effect on such performance characteristics as wear, seal leakage, surface protection, strength, and friction characteristics.

Engine testing would start about one year after program go-ahead. About 5 or 6 test engines would be required if the total development and qualification program time were 3 years. An accelerated program would require a larger number of test engines. The engine test program culminates with an acceptable qualification test (QT). Table V presents the primary types of engine tests performed with each engine in an example 6-engine program.

Engine number 1 is used primarily for the systems, mechanical, and performance testing required to evaluate overall engine and component performance at sea level static (SLS) conditions. It is also used for accelerated endurance testing to provide early assurance of cyclic endurance capability. The second engine is primarily for PFRT assurance and simulated rocket noise tests. For the noise tests, the engine is positioned vertically, subjected to simulated rocket noise, and then put in a test stand and run to determine if the engine has been affected.

The third engine is used primarily for altitude performance testing and inflight start verification. This testing is performed in an altitude 
test facility such as is available at NASA - Lewis or Arnold Engineering and Development Center. Features of this test include the use of inlet distortion screens and preheating of the engine to obtain engine temper atures comparable to those following reentry prior to inflight start. The fourth engine is used primarily for space environmental testing. This series of tests comprises a number of cycles, each consisting of a soak period in a space environmental chamber followed by an engine run in a test stand.

The fifth engine is for the flying test bed program in an aircraft such as a B-52. Either a fixed underwing nacelle or a deployable configuration could be used. Testing would be for performance and particularly for inflight start. The sixth engine is the official PFRT and QT engine.

\section{CONCLUDING REMARKS}

The requirements imposed on the airbreathing engines by the shuttle mission and some of the results from the engine design studies were discussed in this paper. In particular, some of the engine system weight study results were presented, potential problem areas and required engine modifications were identified, and the types of testing required for a development and qualification program were discussed. The airbreathing engine studies, however, were based on a shuttle system concept that is no longer current; that is, a system having a flyback booster and piggyback orbiter. The current shuttle concept features two booster solidrocket motors (recoverable by parachute) and an expendable external hydrogen/oxygen fuel tank. The question that arises, then, is "how valid are the study results obtained?" 
With the significant changes in mission requirements and vehicle design, the engine system weights are not considered to be valid with respect to the current shuttle system. However, the relative insensitivity of orbiter engine system weight to a variation in bypass ratio should not change very much since the deletion of the go-around requirement is somewhat offset by the inclusion of a loiter requirement. With respect to the engines (nonaugmented derivatives of the GE F101 and P \& W F401) selected for detailed study, they still remain as viable candidate engines. In addition, the augmented parent engines become of interest as a result of the deletion of the long cruise and engine-out requirements. Other developmental engines may also emerge as candidates.

With respect to the potential problem areas and required engine modifications, they are still valid since the launch, space, and reentry environments have not changed. If an augmented engine is used, however, modifications associated with augmentator removal need not be considered, but potential problems associated with the afterburner and variable nozzle must be explored. Similarly, the required testing program, except for changes that may be necessitated by the use of an afterburner, remains very much as discussed.

The authors wish to acknowledge that this paper is based on material generated by the shuttle engine design study contractors, General Electric and Pratt \& Whitney. In addition, we wish to thank McDonnell Douglas and North American for providing the vehicle pictures. 


\section{REFERENCE}

1. W. L. Stewart, A. J. Glassman, and S. M. Nosek, "Shuttle Air breathing Propulsion." Paper 71-662 presented at AIAA 7th Propulsion Joint Specialist Conference, Salt Lake City, June 1971. 


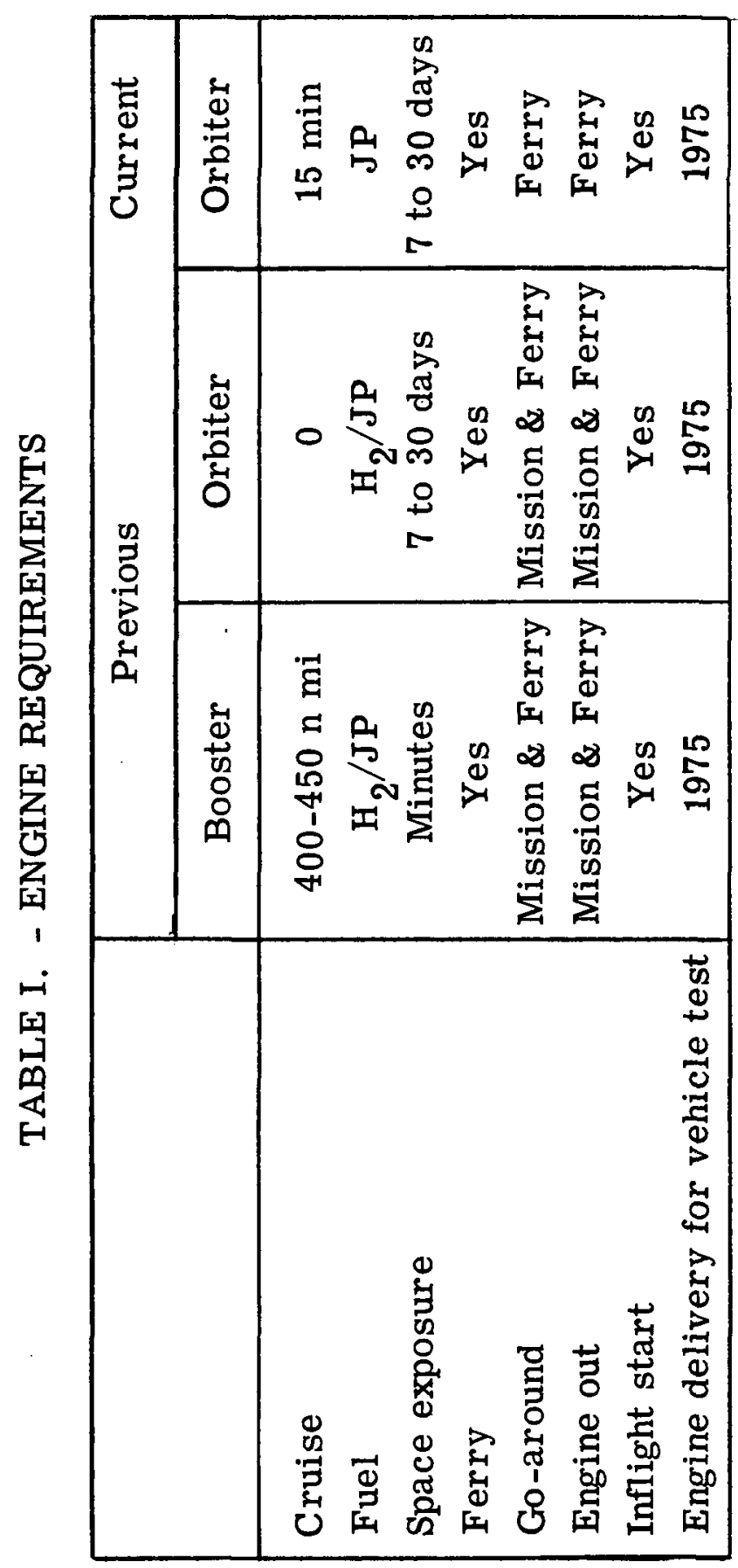




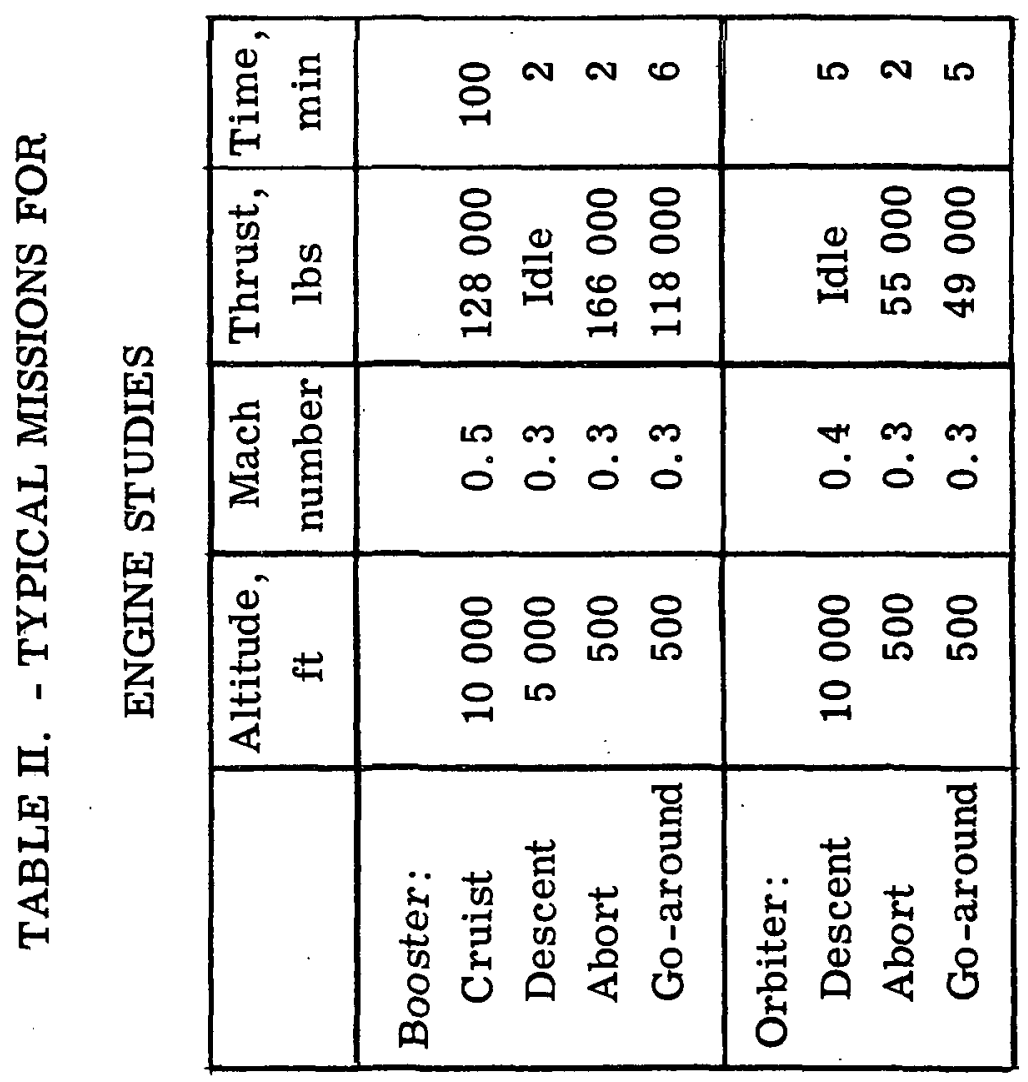




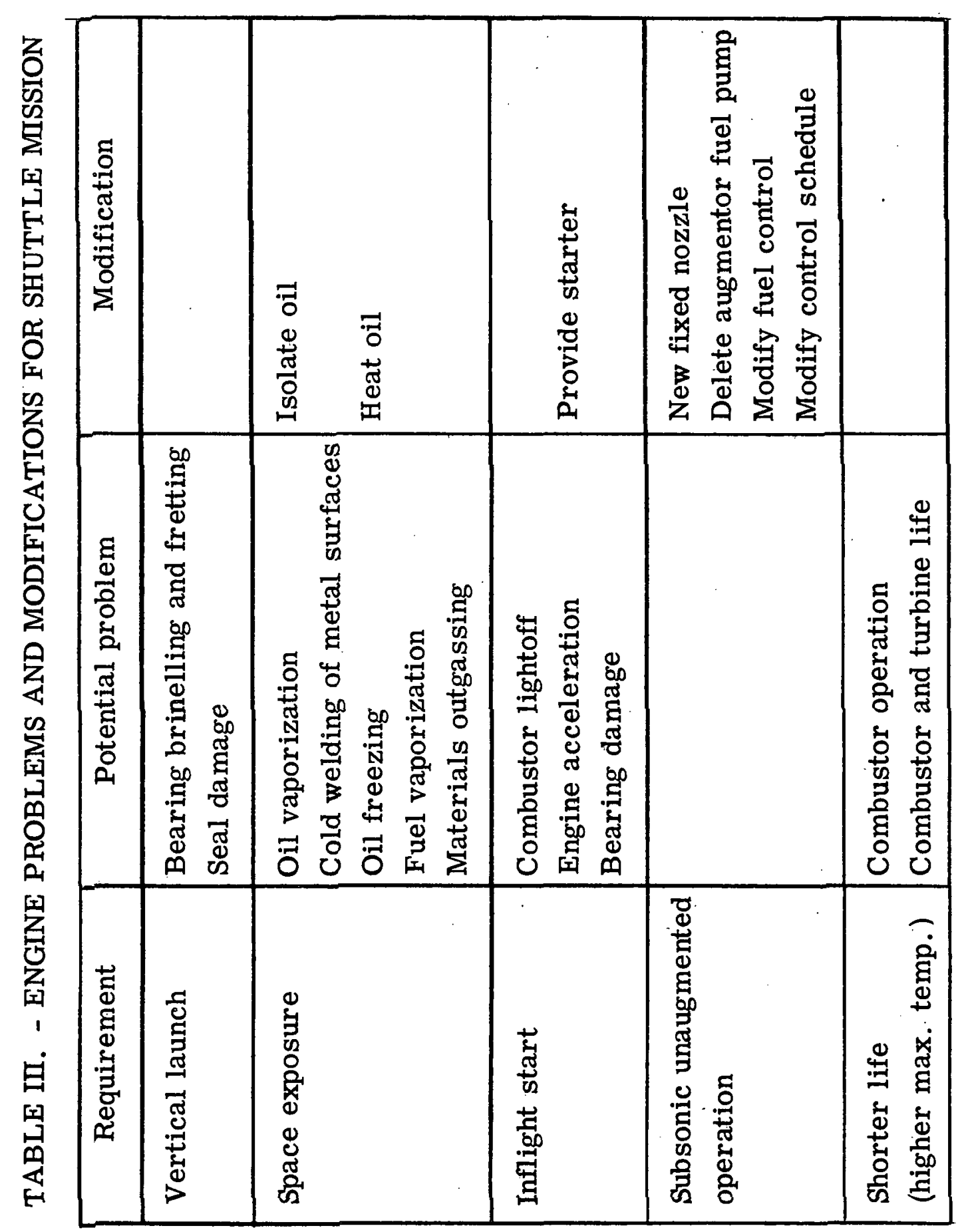


TABLE IV. - COMPONENT TEST REQUIREMENTS

\begin{tabular}{|l|l|}
\hline \multicolumn{1}{|c|}{ Item } & \multicolumn{1}{c|}{ Type of test } \\
\hline Control system & Calibration and operation with required modifications \\
Bearings and seals & Vibratory, dry acceleration, lubricated endurance \\
Nozzle & Cold-and hot-flow tunnel and rig models \\
Combustor & Increased temperature operation, altitude lightoff \\
Lube system & Vacuum storage, inflight start activation \\
Materials & Vacuum exposure of nonmetals \\
\hline
\end{tabular}


TABLE V. - EXAMPLE ENGINE TEST PROGRAM

\begin{tabular}{|c|l|}
\hline $\begin{array}{c}\text { Engine } \\
\text { number }\end{array}$ & \multicolumn{1}{|c|}{ Primary tests } \\
\hline 1 & SLS performance, endurance \\
2 & Launch vibration, PFRT assurance \\
3 & Altitude performance, inflight start \\
4 & Cyclic space environment soaks and SLS runs \\
5 & Flying test bed performance and air start \\
6 & PFRT and QT \\
\hline
\end{tabular}




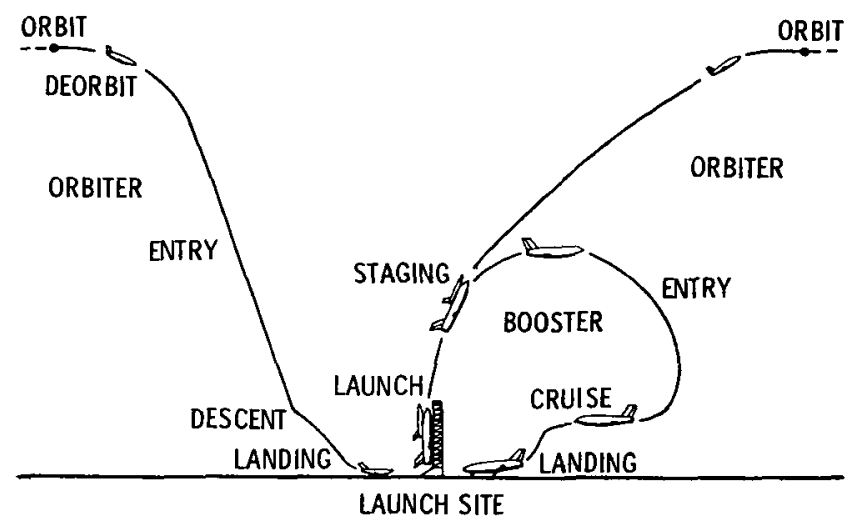

(a) PREVIOUS.

$\infty$
0
0
1
1
1

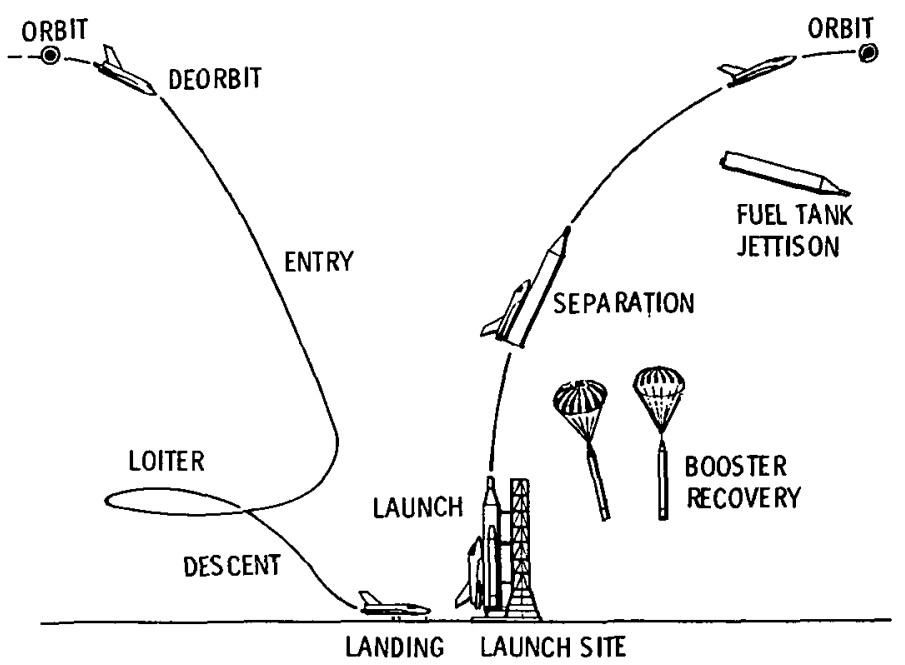

(b) CURRENT.

Figure 1. - Mission flight profile. 



Figure 2. - Airbreathing engine installation on shuttle orbiter (McDonnell Douglas design).

Figure 3. - Airbreathing engine installation on shuttle orbiter (North American design).

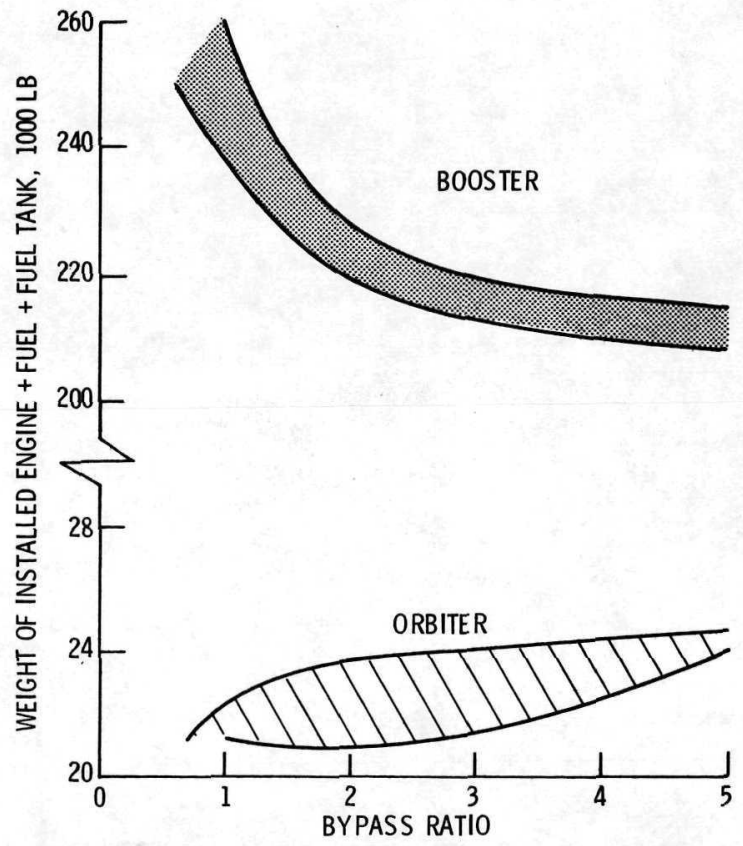

Figure 4. - Effect of bypass ratio on engine system weight. (For mission with flyback booster.) 


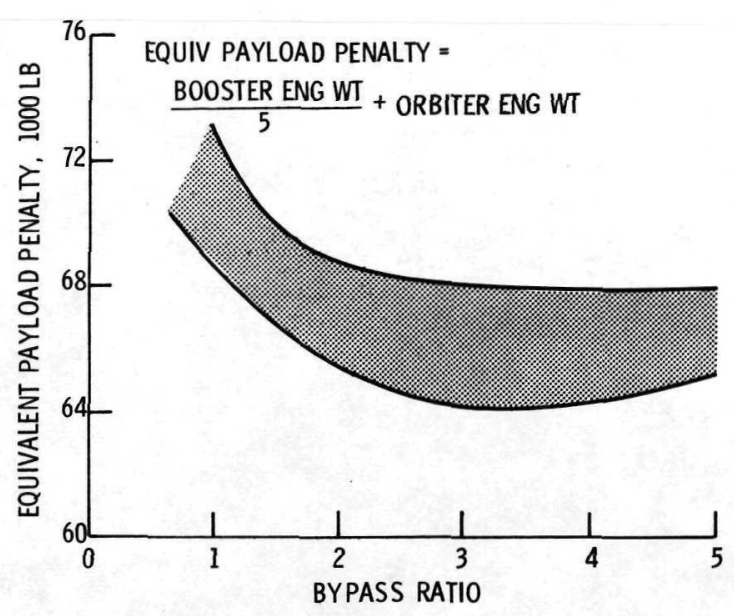

Figure 5. - Effect of bypass ratio on mission payload. (For mission with flyback booster.)



Figure 6. - Shuttle version of Pratt and Whitney F401 engine.

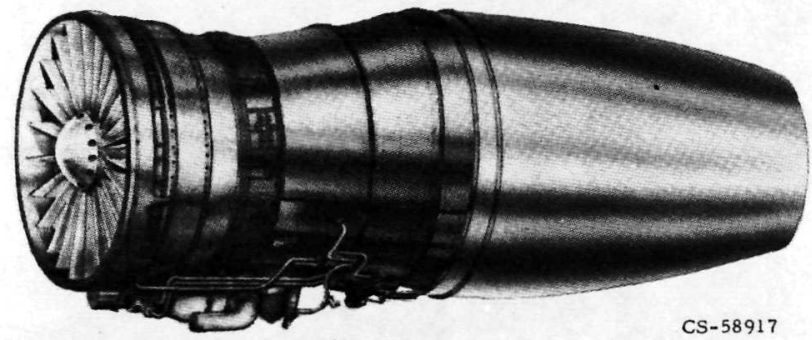

Figure 7. - Shuttle version sketch of General Electric F101 engine. 